\title{
ЭНЕРГЕТИЧЕСКАЯ ПОЛИТИКА СССР КАК ФАКТОР ВЛИЯНИЯ НА ИТАЛИЮ В 1960-Х ГОДАХ
}

\begin{abstract}
Аннотация. С началом международной оттепели СССР стремился найти коммерческих партнёров в западном блоке с целью получения их самых передовых технологий и влияния на их внешнюю политику. Италия была объектом внимания советского руководства. Через компанию ENI, в конце шестидесятых годов были начаты отношения, которые через несколько лет привели к подписанию двух исторических соглашений: для поставок нефти в Италию и для строительства газопровода для доставки газа из Советского Союза в Италию. Итальянский политический класс, соблюдая международные обязательства, сумел добиться своих целей.
\end{abstract}

Ключевые слова: ЭНИ, Маттей, Фанфани, внешнеторговые отношения, экономическая политика Италии.

\section{Возобновление отношений между Римом и Москвой}

1960-е годы представляют собой особо интересный период для изучения советско-итальянских отношений второй половины XX века [Bagnato, 2003; Хормач, 2005; Salacone, 2017]. Двусторонние отношения находились под влиянием глубоких изменений мировой политики - окончания сталинизма и начала разрядки международной напряжённости. Противостояние двух полюсов в конце 1950-х гг. подошло к новой фазе, отличавшейся констатацией того факта, что атомный конфликт между блоками может разрушить цивилизацию [Zubok, 2007]. Соревнование между НАТО и социалистическим блоком заключалось теперь в способности привлечь большую часть государств к своей политической и экономической модели, чтобы таким образом определять будущее международных отношений.

(C) Салаконе Алессандро - научный сотрудник Università degli Studi di Napoli - L'Orientale, сотрудник Института всеобщей истории РАН. Aдpec: 119334, Россия, Москва, Ленинский проспект, д. 32 A,. E-mail: asalac@ gmail.com

Статья написана по гранту РНФ № 17-18-01728, полученному ИВИ РАН.

DOI: http://dx.doi.org/10.15211/soveurope62018134141 
Новые сценарии международного развития влияли на политическую, экономическую и социальную эволюцию в СССР и в Италии, сближая Москву и Рим немыслимым за несколько лет до этого образа. Недавнее открытие архивных фондов того периода как в Италии, так и в России позволило исследовать его с большей объективностью, чем было возможно ранее ${ }^{1}$. Из исследования советской документации следует, что дипломатия СССР обращала особое внимание на Италию, исходя из того, что в перспективе Италия сможет играть близкую к позициям Москвы роль, разрушая монолитность НАТО. В этой стратегии экономические связи и особенно энергетическая политика были принципиальны [Perović, Cold War Energy, 2017: 4]. Ситуация в Италии имела особенные черты для советского наблюдателя: в ней присутствовала самая большая коммунистическая партия Западной Европы, политический курс руководящего класса стремился увеличить вес страны внутри атлантического блока, в том числе благодаря диалогу с социалистическим лагерем, экономическое развитие страны зависело от дешевых ресурсов иностранных партнёров, и т.д. Советские руководители внимательно следили за развитием итальянской политики. В сложное время после XX съезда КПСС они осознали, что лишь посредством сотрудничества с Западом возможен экономический и социальный подъём страны, находившейся в трудных обстоятельствах [Graziosi, 2008: 165]. Принципы мирного сосуществования, которыми вдохновлялись действия советского руководства, благоприятствовали разрядке напряжённости между двумя блоками. Внимание к Италии, стране пограничной между Западом и социалистическим лагерем, было частью этой стратегии.

В Кремле убедились, что улучшение отношений с Римом, благодаря прежде всего укреплению экономических связей, может внести вклад в стабилизацию обстановки на европейском континенте и противостоять возможному стремлению других западных государств обострять отношения между двумя лагерями. Кроме того, отношения с Италией могли быть ценной поддержкой в более широкой внешнеполитической деятельности СССР. Кремль счёл возможным завязать политические отношения с Италией, пользуясь не только традиционными каналами коммунистической партии. В данный контекст вписывалась инициатива Москвы по установлению прямых отношений с некоторыми лидерами парламентского большинства и представителями правительства, регулярных и частых встреч с ними.

\section{Экономические связи и нертяная стратегия}

Торговые связи сыграли решающую роль в “размораживании” застойных советско-итальянских отношений послевоенного периода. В 1950-е гг. развитию торговых отношений больше всего препятствовали партии итальянского парламентского большинства. Они были озабочены ростом советского влияния в Италии, опасаясь его прямого воздействия на политическое равновесие в стране, а также реакции НАТО на увеличение торгового обмена. В то же время итальянские предпринимательские круги (ENI, FIAT, Snia Viscosa, Montecatini, Châtillon, Olivetti, Pirelli, и

${ }^{1}$ Сборник документов из РГАНИ о итало-советских отношениях (1953-1970) опубликован на итальянском языке под названием [L'Italia vista dal Cremlino, 2015].

Современная Европа, 2018, №6 
т.д.) внимательно следили за изменением международной обстановки и в конце пятидесятых годов увидели широкое поле деятельности для торговли.

В декабре 1958 г. Энрико Маттеи, президент ЭНИ, писал: “Европейский запад отличается от Америки. Такая западная густонаселенная и с высококачественной промышленностью страна как Италия нуждается в импорте сырьевых ресурсов для своих заводов, имеет определенную позицию и может найти экономические пункты соприкосновения с Советским Союзом. Италия, с нынешним правительством Фанфани, имеет определенные положительные условия для этого" реломом в экономических отношениях стало подписание в декабре 1957 г. важных долгосрочных торговых протоколов между правительствами двух стран, за которым последовал в 1959 г. визит в СССР министра внешней торговли Дель Бо, ставшего первым членом итальянского правительства, посетившим Москву после Второй мировой войны. Во время встречи с министром внешней торговли СССР Н.С. Патоличевым стороны отметили, что в 1959 г. двусторонний торговый оборот увеличился на $80 \%$ по сравнению с предыдущим годом ${ }^{2}$. Рынок Советского Союза представлял итальянским предпринимателям богатые возможности для торговой экспансии, обусловленные обширной территорией и спросом населения на товары. Рост торговли с СССР представлялось логичным и для итальянской экономики, нуждавшейся в новых рынках для размещения своей продукции и в источниках сырья [Салаконе А., 40 лет вместе. С. 12]. Особую роль в развитии двусторонних связей играли отношения между СССР и “Эни”. Последняя под руководством Э. Маттеи с конца 1950-х гг. создала интегральную систему по переработке нефтепродуктов, самую передовую в мире с технологической точки зрения. Итальянской государственной компании не хватало достаточного снабжения сырцом. Большая часть нефти на предприятиях “Эни” была иностранного происхождения.

Энергетическая политика, которой следовали “Союзнефтэкспорт” и “Эни”, была выгодной для экономик обеих стран, так как закупки сырья наряду с удовлетворением энергетических потребностей итальянской национальной экономики обеспечивали стабильные поступления твердой валюты в бюджет бывшего Советского Союза, что, в свою очередь, способствовало импорту высокотехнологичного оборудования и техники из Италии. Годы перестройки промышленности и экономического бума выявили в Италии нехватку энергоресурсов, в которых нуждалась национальная экономика, и это заставило искать сырье за пределами страны, и часто приходилось соглашаться на условия, навязываемые западными картелями. Импорт из СССР по конкурентоспособным ценам значительных объёмов нефти, а затем и природного газа, отвечал первоочередным интересам итальянской промышленности. Экономический диалог с СССР позволял итальянским предприятиям использовать потенциал огромного советского рынка [Салаконе А., 40 лет вместе. с. 13].

Москва считала Э. Маттеи привилегированным собеседником по нескольким причинам: он был сторонников необходимости открыть итальянский рынок Советскому Союзу, не следовал политике “семи сестер” и развивал самостоятельную по-

\footnotetext{
${ }^{1}$ Историчекий архив ЭНИ (дальше ASENI), Coll. H.III.2, udc. 31, nua 312.

${ }^{2}$ См. Запись беседы министра Н.С. Патоличева с министром внешней торговли Италии Р. Дел Бо, 15/10/1959, РГАЭ, Ф. 413, оп. 13, д. 8506, л. 64.
} 
литику экспансии, был связующим звеном между политическим и экономическим классами. Иными словами, Москва считала “Эни” важным каналом влияния на политику Италии. Неоатлантический курс Рима в некотором смысле оправдывал такую идею, хотя иллюзий было больше. Интересна встреча Э. Маттеи с А.Н. Косыгиным в мае 1960 г., во время неофициального визита первого заместителя председателя Совета министров СССР в Италии. Во время беседы итальянский предприниматель уверял собеседника в том, что “Эни” ставит перед собой цель ослабить позиции международных нефтяных компании и полагается на поддержку $\mathrm{CCCP}^{1}$. Сотрудничество с "Эни” привело к подписанию 12 октября 1960 года контракта на поставку сырой нефти из СССР. Зная о доверии, которым пользовалась “Эни” в СССР, “Союзнефтеэкспорт" включил в контракт выгодный для итальянцев пункт, согласно которому советская нефтяная компания обязалась не продавать нефть другим покупателям в Италии в период с 1961 по 1966 год². Контракт стал ошеломляющей новостью и открыл двери Италии для советской нефти ${ }^{3}$. Советская пресса уделила большое внимание сделке. В газете "Правда" цитировалась часть текста соглашения и были размещены комментарии Э. Маттеи ${ }^{4}$. В “Экономической газете” писали о том, что договор с “Эни” станет примером для будущих договорённостей с другими капиталистическими странами 5 .

Реакция стран НАТО и ЕЭС была решительной. Западные партнеры обвинили ЭНИ в “слепом" выборе ради итальянских интересов без учёта последствий. В НАТО была создана специальная комиссия по изучению вопроса экспорта советской нефти и был предложен эмбарго на экспорт в СССР труб большого диаметра. В циркулярном письме "Standard Oil New Jersey" отмечалось: "Связи между AGIP, Россией и Красным Китаем становятся все больше и больше тесными. (...) Достигнутое соглашение позволяет AGIP получить большие дивиденды, которые будут иметь катастрофические последствия для ближневосточных импортёров. (...) Амбиции Энрико Маттеи использовать Россию как инструмент, чтобы вытеснять иностранные компании из Италии, (...) рискуют сделать Италию рабом социалистического блока" держки руководства правящей Христианско-демократической партии и без посредничества Итальянской коммунистической партии. Поворотным моментом стало решение итальянского правительства выдавать СССР долгосрочные кредиты на экспорт [Bagnato, 2003: 294]. Кремль воспринял такое решение положительно, тем

\footnotetext{
1 Запись беседы А.Н. Косыгина с президентом ЭНИ, Енрико Маттеи, 31/5/1960, in АВП РФ, Ф. 098 , оп. 43, р. 60, д. 12, лл. 37-42.

2 Письмо президента Союзнефтеэкпорт ЭНИ, 20/4/1960, в ASENI, Coll. H.IV.3, udc 30, nua 6AD, а также [Салаконе A., 40 лет вместе. с. 14].

${ }^{3}$ Текст соглашения ENI-Союзнефтеэкспорт в ASENI, Coll. AZ.II.2, udc 0057, nua 18AO.

${ }^{4}$ Новое крупное советско-итальянское соглашение, Правда, 12/10/1960.

5 Рачков В., Крупный успех советско-итальянской торговли, Экономическая газета, 22/10/1960.

${ }^{6}$ Circolare della Standard Oil a tutte le sue affiliate e dipendenze all'estero, da dott. Ruffolo a dott. Ratti, riservata, 3/11/1960, in ASENI, Coll. AZ.I.1, udc 002, nua 7DA.
} 
более что Москва уже давно предлагала итальянцев пойти на такой шаг с целью постройки нефтегазопроводов ${ }^{1}$.

Анализ показывает, что итальянцы понимали ситуацию, но ради выгодных экономических условий были готовы идти на компромиссы с СССР. Благодаря советской нефтяной стратегии Италия в 1958-1959 гг. стала главным импортёром советского газа среди несоциалистических стран ${ }^{2}$. Заключение контракта между Эни и “Союзнефтеэкспортом" придало импульс взаимовыгодному развитию италосоветских двусторонних отношений и стало предвестником переговоров о заключении нового долгосрочного контракта на поставку 28 млн т сырой нефти до 1971 г. в обмен на поставки товаров и услуг компаний группы “Эни”.

\section{Газовая стратегия}

В 1960-е гг. в СССР бурно развивалась газовая промышленность и строительство широкой сети магистральных газопроводов. Решение о создании более эффективной инфраструктуры было принято на XXII съезда КПСС в 1961 г. Достичь цели было бы невозможно при использовании только отечественных технологий. Италия в силу высокого уровня модернизации своего промышленного производства представляла собой страну, с которой было выгодно расширять сотрудничество.

“Эни”стала одной из первых итальянских компаний, к которой обратилось советское правительство. Внешнеторговый оборот между СССР и Италией в период с 1963 по 1964 г. держался на одном уровне 3 . В 1965 г. двусторонние торговые отношения СССР и Италии испытали рост, активизировалось сотрудничество в энергетической сфере [Salacone A. La diplomazia del dialogo, 1958-1963: 325]. Ocoбоe внимание было сосредоточено на огромных запасах природного газа, которыми обладал Советский Союз. Именно в те годы “Эни”, испытывая острую необходимость как в обеспечении безопасности поставок, так и в более приемлемых ценах на энергоресурсы, пошла на диверсификацию основные источники энергии. Компания приняла решение начать импорт газа из СССР, несмотря на наличие существенных трудностей технического и правового характера, связанных с пересечением территории других стран [Салаконе, 40 лет вместе. с. 15]. По ряду причин, связанных с позицией двух правительств, переговоры не привели к быстрому результату.

Вопрос обсуждался в ЦК КПСС. Министр иностранных дел СССР А.А. Громыко горячо поддержал предложение, тем более что “Эни” могла предоставить материалы и оборудование, необходимые для строительства газопровода в счёт поставок советского газа ${ }^{4}$. Оплата газа оборудованием и трубами была весьма выгодна

\footnotetext{
${ }^{1}$ Запись беседы министра внешней торговли СССР Патоличева с послом Италии Пьетромарки, 13/1/1960, в РГАЭ, Ф. 413, оп. 13, д. 8744, лл. 185-188.

${ }^{2}$ Совершенно секретная телеграмма n. 47/18093 от 12/9/1960 МИД Италии председателю Совета Министров, переписка с другими адресатами: Центральный государственный архив Италии (дальше ACS), Fondo PCM, Serie 1959-1961, b. 15.2.3789. Согласно данным этого документа, Италия была первым импортёром советской нефти (2.360.300 тонн).

3 Запись беседы с итальянским министром внешней торговли Б. Маттарелла, 19/10/1964, РГАЭ, Ф. 413, оп. 31, д. 284, лл. 297-303.

${ }^{4}$ Запись министра иностранных дел СССР Громыхо, РГАНИ, Ф. 3, оп. 16, д. 783, лл. 88-89. Современная Европа, 2018, №6
} 
СССР, о чём свидетельствует тот факт, что запрос Министерства топливной промышленности СССР на количество труб (5900 км) и компрессорных станций был рассчитан на осуществление других проектов на территории страны ${ }^{1}$. Центральный Комитет, изучив вопрос, решил отложить принятие решения ${ }^{2}$. Переговоры возобновились после визита в Италию А.А. Громыко в мае 1966 года. Проект газопровода столкнулся с техническими сложностями, которые были связаны с государственным финансированием, а также с тем, что итальянское правительство, опасаясь международной реакции на строительство газопровода, не спешило [Salacone A. La diplomazia del dialogo, 1958-1963: 357-358]. Изначально Советский Союз предложил пустить газопровод через территорию Венгрии и Югославии. Впоследствии было решено проложить его маршрут по Чехословакии и Австрии ${ }^{3}$.

Одним из основных препятствий для Италии стал вопрос государственного кредитования. Работа делегаций над содержанием соглашения велась на протяжении всего 1966 года. Причины, по которым руководство “Эни” активно отстаивало в итальянском правительстве важность заключения соглашение, были, безусловно, убедительны: добыча и потребление природного газа в Италии в 1965 г. достигли 7,7 млрд куб. м. Ожидалось, что в последующие годы собственного производства будет недостаточно для обеспечения растущих потребностей. Огромные запасы газа в СССР могли бы стать для Италии источником энергоресурсов на самых выгодных условиях ${ }^{4}$. В начале 1967 г. Москва оказывала настойчивое давление на Рим, чтобы вывести переговоры из тупиковой ситуации. Посол СССР в Италии Н.С. Рыжов неоднократно настаивал на необходимости скорейшего достижения соглашения, намекая на то, что в противном случае Советский Союз начнёт рассматривать другие предложения 5 . Ситуация разрешилась 14 апреля 1967 г., когда правительство Италии дало наконец положительный ответ после межведомственного заседания под председательством премьер-министра Альдо Моро и управляющего Банка Италии Гуидо Карли ${ }^{6}$. Одобрение сделки не означало завершение переговоров. В течение трёх последующих лет они продолжались в Москве для обсуждения финансовых и коммерческих аспектов сделки.

Заключение соглашения по газопроводу произошло 10 декабря 1969 г.; его подписали заместитель министра внешней торговли СССР Н.Г. Осипов и президент концерна “Эни” Эудженио Чефис. Длительность сделки составила 20 лет; она предусматривала поставку 6 млрд куб. м газа в год. В общей сложности СССР обязывался поставить в Италию более 100 млрд куб. м природного газа. Начало поставок планировалось через три года после подписания контракта, однако в действитель-

\footnotetext{
${ }^{1}$ Lettera di P. Landolfi da Mosca a Eugenio Cefis, 21/8/1965, in ASENI, Coll. BA.IV.6, Udc 355, Nua 1C46, а также [Салаконе, 40 лет вместе. с. 15, 16].

2 Постановление 218/Х Президиума ЦК КПСС от 21/10/1965, РГАНИ, Ф. 3, оп. 18, д. 376, л. 5.

${ }^{3}$ Appunto riservato per l'ing. Zola del 29/11/1966, in ASENI, Coll. O.III.3, udc 69, nua 2 DF5.

4 Appunto sulla situazione delle trattative con il governo sovietico per l'importazione di gas, 11/8/1966, in ASENI, Coll. O.III.3, udc 69, nua 2DF5.

${ }^{5}$ Appunto di Franco Briatico per il dott. Pirani, 20/2/1967, in ASENI, Coll. U.V.1, ude 159, nua 2FD6.

${ }^{6}$ Accordo URSS-ENI per il metanodotto, in "Gazzetta del Popolo”, 15/4/1967 а также [Салаконе, 40 лет вместе. с. 15].
} 
ности первый газ пошел 1 мая 1974 г. Советский Союз, в свою очередь, получил кредит в размере 200 млн долл. на покупку итальянских труб и оборудования для газовой промышленности [Салаконе, 40 лет вместе. С. 18].

Газопровод обладал интересными техническими и конструкционными характеристиками. Соглашение предусматривало поставку газа на чешско-австрийскую границу, в связи с чем было создано совместное предприятие с компанией ÖMV, ведущей газовой компанией Австрии. Планировалось, что оно займётся строительством и управлением части газопровода, проходившей по территории альпийской республики, длина отрезка которого составляла около 380 км ${ }^{1}$.

Закупка природного газа у СССР ознаменовала второй важный этап в истории двусторонних отношений в области энергетики. Соглашение было уникальным и первым в своём роде. Официальное открытие газопровода состоялось 8 июня 1974 г. в присутствии премьер-министра Италии Мариано Румора, министра газовой промышленности СССР С.А. Оруджева и заместителя министра внешней торговли СССР Н.Г. Осипова.

$* \quad * \quad *$

Новое соглашение о строении газопровода стало не только краеугольным камнем энергетической политики Италии, но также частью европейской политикоэкономической системы. Этот и другие газопроводы, которые еще предстояло построить, открывали совершенно новые перспективы [Салаконе, 40 лет вместе. С. 19]. Советская энергетическая стратегия в отношении Рима достигла многих своих целей. Между Римом и Москвой в 1960-е гг. установились близкие отношения. Не удивительно, что они вызывали тревогу у евроатлантических партнёров. Итальянские экономические круги, а в некоторые моменты и политические, сумели создать у СССР впечатление, что они ищут оригинальные решения в международных вопросах. Со своей стороны, Москва использовала стремление Италии к достижению дешевых природных ресурсов, чтобы предложить выгодные соглашения с высоким политическим потенциалом и надолго связать судьбу экономики Италии с советскими ресурсами. Можно со всей уверенностью утверждать, что в том десятилетии были заложены основы советско-итальянских отношений и определились черты, которые будут отличать двусторонние связи в последующем. В этом процессе энергетическая политика сыграла решающую роль.

Список литературы

Салаконе А., 40 лет вместе. История сотрудничества Гаспрома с ЭНИ. https://www.eni.com/ru_RU/attachments/pdf/eni-gazprom-bassa.pdf

Хормач И.А. (2005) СССР - Италия и блоковое противостояние в Европе. М., ИРИ РАН.

References

Accordo URSS-ENI per il metanodotto, in "Gazzetta del Popolo", 15/4/1967.

\footnotetext{
${ }^{1}$ Documentazione relativa a costruzione gasdotto, in ASENI, Coll. AZ.IV.6, udc. 44, nua A94.
} 
Bagnato B. (2003) Prove di Ostpolitik. Politica ed economia nella strategia italiana verso 1'Unione Sovietica, 1958-1963. Firenze: Leo S. Olschki.

Graziosi A. (2008) L'URSS dal trionfo al degrado. Storia dell'Unione Sovietica. 1945-1991. Bologna: Il Mulino, c. 165.

Hormach I.A. (2005) SSSR - Italiya i blokovoe protivostoyanie v Evrope. M., IRI RAN.

L'Italia vista dal Cremlino, (2015) Сост. A. Roccucci, F. Bettanin, A. Salacone, Roma, Viella.

Perović J., (2017) Cold War Energy. A Transnational History of Soviet Oil and Gas. Cham: Palgrave macmillan, c. 4.

Salacone A. (2017) La diplomazia del dialogo. Italia e URSS tra coesistenza pacifica e distensione, 1958-1963. Roma: Viella.

Salakone A., 40 let vmeste. Istoriya sotrudnichestva Gasproma s EHNI.

https://www.eni.com/ru_RU/attachments/pdf/eni-gazprom-bassa.pdf

Salacone A. La diplomazia del dialogo. Italia e URSS tra coesistenza pacifica e distensione, 19581963 , cc. 325.

Zubok V.M. (2007) A failed Empire: the Soviet Union in the Cold War from Stalin to Gorbachev. Chapel Hill: The University of North Carolina Press.

\section{Energy Policy of the USSR as a factor of the Influence on the Italy in 1960s}

Author. Salakone A., Senior Researcher at "Università degli Studi di Napoli - L-Orientale", associate of the Institute of General History, Russian Academy of Sciences. Address: 32A, Leninsky prospect, Moscow, 119334. E-mail: asalac@gmail.com

Abstract. With the start of international detente, the USSR searched for commercial partners in the Western bloc with the aim of adopting the most advanced technologies and influencing their foreign policies. Italy was one of the object of the Kremlin's attention. Through the ENI company, at the end of the 60s, Moscow and Rome launched their commercial relations which, in a few years time, led to the signing of two historical agreements on the supply of oil to Italy and on the construction of pipeline to bring gas from the Soviet Union to Italy. The Italian political class, while respecting international commitments, managed to elaborate bold political decisions to achieve its goals.

Key words: ENI, Mattei, Fanfani, Commercial relationship, political economics, Italia, Detente.

DOI: http://dx.doi.org/10.15211/soveurope62018134141 